by a proton-nucleon collision, the incident proton will require a kinetic energy of at least $5.6 \times 10^{9}$ electron volts. At present only one particle accelerator, the Berkeley 'Bevatron', exists which is designed to reach this energy. At this energy the production of antiprotons is not expected to be very copious, and their abundance relative to other particles formed will probably be far smaller than in many cosmic ray phenomena which have already been extensively investigated. The problem of the conclusive identification of the antiproton may be a difficult one for some time to come. A direct mass and sign measurement might be expected to identify it. However, this would require a high precision to distinguish it from known negative heavy mesons of mass greater than half the proton mass. Further, any such direct mass and sign determination could, in itself, always be attributed to a new type of negative heavy meson.

There is a characteristic feature of an antiproton that should render its identification more simple. On coming to rest in matter, an antiproton should be attracted into the nucleus of an atom and annihilate itself and one ordinary proton. 'This process, liberating as fast mesons (or less probably $\gamma$-rays) twice the rest energy of the incident particle, is by definition unique to an antiparticle, and should be readily observed. One cosmic ray event has been seen in a multiplate cloud chamber by DeStaebler, Bridge, Courant and Rossi (Bull. Amer. Phys. Soc., 29, No. 4, 74 ; 1954), which is consistent with this process, and hard to reconcile with an alternative explanation. Within the past year the use of large blocks of nuclear emulsions, and the combination of magnet and multiplate cloud chambers, have both greatly increased the amount of information that may be obtained from the observation of a single particle. It is quite possible that with the aid of these techniques conclusive evidence for the existence of the antiproton may be found in the near future. Moreover, it may become possible to identify the annihilation products of machine-produced antiprotons by $a$ counter experiment, even if the particle is not detected.

\section{Recollections of Lord Rutherford}

At therequest of a number of its Fellows, the Physical Society has reprinted the first five of its Rutherford Lectures in a booklet entitled "Rutherford by those who knew him" (pp. 69 ; from the Physical Society, 1 Lowther Gardens, London, S.W.7 ; 1954 ; 5s. to members or $8 s .6 d$. to non-members, with $6 d$. postage). All five Lectures are reminiscent in character and are obviously tributes by men who, like so many, if not all, of Rutherford's research workers, had fallen under the magic spell of their chief. There are a number of illustrations, some of which are rather charming in that they are snapshots, for the most part rather poor ones, taken from photographic albums and no doubt highly prized by their owners; unfortunately, the reproductions are very poor. The Lectures are by Prof. H. R. Robinson (Manchester period); Sir John Cockcroft (Cambridge period); Prof. M. L. Oliphant; Dr. E. Marsden; and Dr. A. S. Russell (Manchester period). Perhaps the Lectures by Prof. Robinson, Sir John Cockeroft and Dr. Russell are the more personal, or even anecdotal, of the five; Prof. Oliphant's Lecture is an attempt, in all too short a space, to appraise the impact of Rutherford and his work upon the science and life of the present time, and Dr. Marsden, as befits the only New Zealander, for the most part emphasizes the import- ance of Rutherford's early New Zealand background in the development of his character. The Lectures make fascinating reading, because their subject was a fascinating personality. Perhaps none has summed up Rutherford better than the late Sir James Jeans in a tribute shortly after Rutherford's death : ". . . In his flair for the right line of approach to a problem, as well as in the simple directness of his methods of attack, he often reminds us of Faraday, but he had two great advantages which Faraday did not possess-first, exuberant bodily health and energy, and second, the opportunity and capacity to direct a band of enthusiastic co-workers. Great though Faraday's output of work was, it seems to me that to match Rutherford's work in quantity, as well as in quality, we must go back to Newton. Rutherford was ever the happy warrior-happy in his work, happy in its outcome, and happy in its human contact".

\section{Nuclear Reactor in Stockholm}

ON July 13 a nuclear reactor moderated with heavy water and using natural uranium was started in Sweden. The reactor, which is of the $C P 3$ type, has been built by the Atomic Energy Co. in Stockholm, a company jointly owned by the Government and private industry. The reactor is located in an underground room in the neighbourhood of the Royal Institute for Technology. Construction was started in the middle of 1951. The designed power is $300 \mathrm{~kW}$. and the heat is dissipated by circulating the moderator through a heat exchanger, where it is cooled by air.

\section{Work of the British Council}

THE tribute to the value of the work of the British Council which was paid six years ago by the Select Committee on Estimates was fully endorsed on both sides of the House of Commons in the debate on Overseas Information Services on July 6 . That debate arose essentially out of the failure of the Government to reach any decision on the recommendations for the re-organization of these services in the report presented a year ago by Lord Drogheda's Committee. The second annex to that report, of which a summary was published in April last (Overseas Information Services. Miscellaneous No. 12 (1954) : Summary of the Report of the Independent Committee of Enquiry into the Overseas Information Services. (Cmd. 9138.) Pp. 56. (London : H.M.S.O., 1954.) $1 s, 9 d$. net), reviews the work and requirements of the British Council and, while making proposals for curtailment and rearrangement of the Council's work in Europe, stresses the value of the work being done elsewhere. The Drogheda Committee was well impressed with the standard of the staff in those British Council centres it visited, and directs attention in this report to the importance of establishing a long-term programme for British Council work overseas and sticking to it if staff of high quality are to be attracted and freed from the atmosphere of frustration and uncertainty in which the Council works to-day. The recommendations of the Drogheda Committee, including provisions for pensions, staff allowances, etc., would increase the total annual grants to the British Council by about $£ 630,000$, thus restoring the position to about what it was during 1948-49. What it believes the British Council needs more than anything else is a five-year programme of development with some guarantee that the necessary funds will be provided for its execution. 